\title{
Environmental influences on antibody-enhanced dengue disease outcomes
}

\author{
Daniel Guerreiro Diniz', César Augusto Raiol Fôro', Maíra C Pereira Turiel', \\ Marcia CK Sosthenes', Sâmia Demachki', Giovanni Freitas Gomes ${ }^{1}$, Carla M Damasceno Rego', \\ Marina Cutrim Magalhães', Brunno Gomes Pinho², Juliana Pastana Ramos ${ }^{3}$, \\ Samir M Moraes Casseb ${ }^{4}$, Maysa de Vasconcelos Brito ${ }^{4}$, Eliana Vieira Pinto da Silva ${ }^{4}$, \\ Marcio Roberto Teixeira Nunes ${ }^{4}$, José Antonio Picanço Diniz ${ }^{4}$, Colm Cunningham ${ }^{5}$, \\ Victor Hugh Perry ${ }^{6}$, Pedro F Costa Vasconcelos ${ }^{3,4} /{ }^{+}$, Cristovam W Picanço Diniz ${ }^{1}$
}

\footnotetext{
'Laboratório de Investigações em Neurodegeneração e Infecção, Hospital Universitário João de Barros Barreto, Instituto de Ciências Biológicas, Universidade Federal do Pará, Belém, PA, Brasil ${ }^{2}$ Centro de Estudos Superiores do Estado do Pará, Belém, PA, Brasil ${ }^{3}$ Universidade do Estado do Pará, Belém, PA, Brasil ${ }^{4}$ Instituto Evandro Chagas, Ananindeua, PA, Brasil ${ }^{5}$ Trinity College, Dublin 2, Ireland ${ }^{6}$ School of Biological Sciences, University of Southampton, Southampton, UK
}

Because an enriched environment (EE) enhances T-cell activity and T-lymphocytes contribute to immunopathogenesis during heterologous dengue virus (DENV) infections, we hypothesised that an EE increases dengue severity. To compare single serotype (SS) and antibody-enhanced disease (AED) infections regimens, serial intraperitoneal were performed with DENV3 (genotype III) infected brain homogenate or anti-DENV2 hyperimmune serum followed 24 h later by DENV3 (genotype III) infected brain homogenate. Compared AED for which significant differences were detected between the EE and impoverished environmental (IE) groups (Kaplan-Meyer log-rank test, $p=$ 0.0025), no significant differences were detected between the SS experimental groups (Kaplan-Meyer log-rank test, $p=0.089)$. Survival curves from EE and IE animals infected with the AED regimen were extended after corticoid injection and this effect was greater in the EE than in the IE group (Kaplan-Meyer log-rank test, $p=0.0162$ ). Under the AED regimen the EE group showed more intense clinical signs than the IE group. Dyspnoea, tremor, hunched posture, ruffled fur, immobility, pre-terminal paralysis, shock and death were associated with dominant T-lymphocytic hyperplasia and presence of viral antigens in the liver and lungs. We propose that the increased expansion of these memory T-cells and serotype cross-reactive antibodies facilitates the infection of these cells by DENV and that these events correlate with disease severity in an EE.

Key words: experimental dengue infection - enriched environment -

antibody-enhanced dengue disease - serial dengue infection - T-lymphocytes

Clinical and pathological evidence implicating abnormal cytokine release as the main mediator of disease and an increased risk of severe dengue disease have been described during secondary dengue virus (DENV) infections (Kurane \& Ennis 1992). Indeed elevated levels of tumour necrosis factor (TNF)- $\alpha$ have been detected in dengue haemorrhagic fever/dengue shock syndrome (DHF/DSS) patients (Vitarana et al. 1991, Hober et al. 1993, Nguyen et al. 2004) and the production of this cytokine was correlated with increased numbers of macrophages/monocytes (de-Oliveira-Pinto et al. 2012), which are potent phagocytic cells and primary targets for DENV infection (Kang-

Financial support: CNPq (300460/2005-8, 301955/2007-7, 471444/2006-5, 454737/2010-6), INCT-FHV/CNPq/CAPES/ FAPESPA (573739/2008-0), FINEP/FADESP (01.04.0043.00), PROPESP-UFPA-FADESP

SMMC, EVPS, JAPD, MRTN, CWPD and PFCV are supported by INCT-FHV/CNPq. CWPD is supported by IBNnet/FINEP.

+ Corresponding author: pedrovasconcelos@iec.pa.gov.br

Received 15 May 2012

Accepted 2 October 2012 wanpong et al. 1995, Jessie et al. 2004). These cells express all three classes of $\mathrm{FC} \gamma \mathrm{R}$ making them especially prone to DENV entry in the form of virus-antibody immune complexes (Mathew \& Rothman 2008). In addition, recent studies have demonstrated that DENV-specific memory Tcells from a prior infection respond to heterologous DENV serotypes with an altered cytokine profile and that the level of activation and expansion of these memory cells during acute DENV infection correlates with the disease severity (Rothman 2010). In addition, significant cross reactivity between DENV serotypes was shown in CD8(+) T-cells after a naturally acquired primary infection with differential T-cell receptor signalling after stimulation with homologous and heterologous peptides (Friberg et al. 2011). DENV entry is facilitated by the phagocytosis of immune complexes via Fc receptors on monocytes (Daughaday et al. 1981) and studies of immune responses have reported circulating immune complexes and complement activation during the fever-to-defervescence period in which haemorrhage, plasma leakage and/or circulatory failure occur in patients with DHF and/or OSS (Ruangjirachuporn et al. 1979, Wang et al. 2006).

In endemic areas, where DHF incidence remains high, mosquito vectors are abundant and multiple in- 
fections are often thought to involve different serotypes (Gubler \& Meltzer 1999, Thomas et al. 2003, Suaya et al. 2009). In addition, an analysis of repeated hospital admissions for dengue showed that at least $10 \%$ of repeat dengue admission patients may correspond to a third or fourth infection with all secondary admissions due to secondary dengue infection (Gibbons et al. 2007). Because most DENV infections are asymptomatic, it is reasonable to assume that a number of patients from endemic areas hospitalised with severe dengue disease may have been exposed to multiple infections. Thus, we have compared the outcomes of two different models of DENV infection: one induced by serial infections with a single serotype (SS) and one induced by multiple serotypes of DENV to enhance the disease through antibody cross reactivity. In this report, we used albino Swiss mice to model antibody-enhanced dengue disease after multiple infections and tested the influence of enhanced T-cell mobilisation on dengue disease severity.

An enriched environment (EE) has been defined as that which offers social interactions with con-specifics and the stimulation of exploratory and motor behaviour with periodic changes in the variety of toys, ladders, tunnels, ropes, bridges and running wheels available for voluntary physical exercise. In contrast, an impoverished environment offers standard cages with reduced sensorial, motor and cognitive stimulation (van Praag et al. 2000). Recent studies have demonstrated that an EE enhances T-cell mobilisation during viral infections (de Sousa et al. 2011) and a greater number of infected target T-cells may contribute to higher viraemia and the excess cytokine levels observed in severe dengue disease (Boonnak et al. 2011). Therefore, we hypothesised that environmental enrichment would exacerbate the clinical symptoms and mortality of DENV infection.

\section{MATERIALS AND METHODS}

We used adult female albino Swiss mice obtained from an outbred colony at the Animal Care Facility of the Evandro Chagas Institute and the mice were handled in accordance with the Principles of Laboratory Animal Care (National Institute of Health). All studies were approved by the institutional animal care committee of the Evandro Chagas Institute, protocol 0061/2009. The mice were maintained with 12 -h dark and light cycles, at a room temperature of $22 \pm 2^{\circ} \mathrm{C}$ and had free access to water and food.

Experimental groups and inoculation - Fig. 1 shows the experimental time line. We performed serial intraperitoneal (i.p.) injections following one of two experimental protocols. Under the first protocol [impoverished environmental (IE): $n=13$; EE: $n=15$ ] all subjects received i.p. injections every other day with infected brain homogenate containing $0.014-0.087$ viral copies $/ \mathrm{mL}$ of DENV3 (genotype III) (SS group) until the day of sacrifice. Under the second protocol (IE: $\mathrm{n}=18$; EE: $\mathrm{n}=$ 16), all subjects received i.p. injections with infected brain homogenate containing a similar number of viral copies of DENV3 (genotype III) once per day for six days. The animals were i.p. inoculated with diluted anti-
DENV2 hyperimmune serum containing anti-DENV2 antibodies (1:32 dilution) every other day. Each injection was followed $24 \mathrm{~h}$ later by injection with DENV3 (genotype III) infected brain homogenate until the day of sacrifice to simulate antibody-enhanced DENV disease (AED group). Animals were sacrificed when they exhibited severe clinical symptoms including dyspnoea, tremor, hunched posture, ruffled fur, immobility, preterminal paralysis, shock and death or when burrowing activity was below $40 \%$ for two consecutive weekly measurements. Control subjects received equal volumes and dilution of anti-DENV2 hyperimmune serum followed $24 \mathrm{~h}$ later by uninfected brain homogenate. On the 38th days post-inoculation (d.p.i.), the subjects in the AED group received a single intramuscular (i.m.) injection of glucocorticoid $(26 \mathrm{mg} / \mathrm{kg}, 1: 1 \mathrm{mixture}$ of acetate and betamethasone sodium phosphate) to reduce T-lymphocyte proliferation and function and to determine the impact of glucocorticoids on the Kaplan-Meyer survival curves. This combination of glucocorticoids becomes effective 30 min after injection and remains active for four weeks.

All animals from the two experiments were nine month old, female albino Swiss mice housed from weaning under either impoverished or enriched conditions

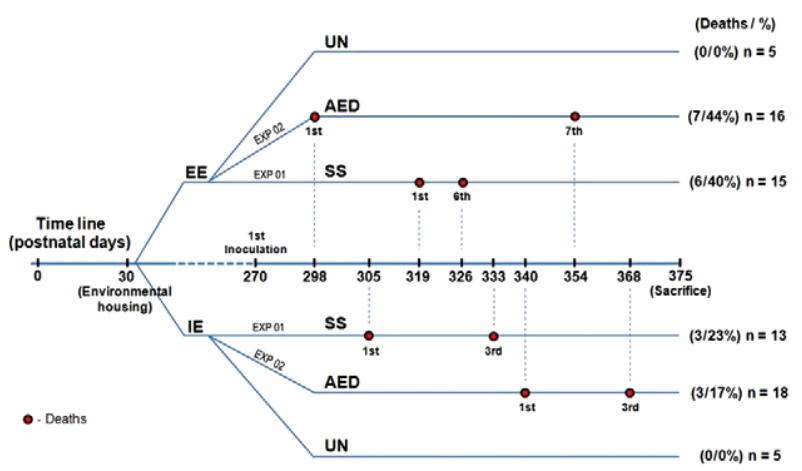

Fig. 1: experimental time line. Animals were housed either in enriched or impoverished environments on the 30th postnatal day. We performed serial intraperitoneal (i.p.) injections following one of two experimental protocols. In the 1st experiment (EXP 01) [impoverished environmental $(\mathrm{IE})=13$; enriched environment $(\mathrm{EE})=15]$ all subjects received a series of every other day i.p. injections of infected brain homogenate [single serotype (SS) group] until the day of sacrifice. In the EXP 02 (IE $n=18$; EE $n=16$, all subjects received a series of i.p. injections of infected brain homogenate containing similar number of viral copies of dengue virus (DENV)3 (genotype III) once a day, during six days and then every other day they were i.p. inoculated with anti-DENV2 hyperimmune diluted serum containing antiDENV2 antibodies (1:32), followed $24 \mathrm{~h}$ later by DENV3 (genotype III) infected brain homogenate until the day of sacrifice [antibodyenhanced DENV disease (AED) group]. The days of sacrifice were different in different animals and they coincided with the presence of clinical signs including dyspnoea, tremor, hunched posture, ruffled fur, immobility, pre-terminal paralysis, shock and deaths or alternatively when burrowing activity reduced below $40 \%$ during two consecutive weekly measurements. Control subjects received equal volumes and dilution of anti-DENV2 hyperimmune serum followed $24 \mathrm{~h}$ later by uninfected brain homogenate. Note that the number of deaths in $\mathrm{EE}$ groups $(\mathrm{SS}=40 \%$; $\mathrm{AED}=44 \%$ ) was significantly higher than in IE the groups ( $\mathrm{SS}=23 \%$; $\mathrm{AED}=17 \%$ ). $\mathrm{UN}$ : uninfected group. 
(Fig. 2, movie S1). Enriched conditions comprised of two-level wire cages $(100 \times 50 \times 100 \mathrm{~cm})$ with toys made of different forms of plastic, wood and metal of different colours, that were changed periodically. Each EE cage housed 15-20 young mice. Water and food were delivered to the top and bottom levels, respectively. Impoverished conditions consisted of plastic cages $(32 \times 39 \times 100 \mathrm{~cm})$ without equipment or toys. Each IE cage housed 15-20 young mice. All mice had free access to water and food.

Infected brain homogenates - Neonatal (2 day old) mice were intracerebrally infected with $10 \mu \mathrm{L}$ of supernatant from $\mathrm{C} 6 / 36$ cells infected with either $1.33 \times$ $10^{3}$ or $7.78 \times 10^{3} \mathrm{cp} / \mathrm{mL}$ of DENV3 (genotype III) obtained from human serum samples (cases ROND 2929 and ROND 3115, respectively). Upon presenting clinical signs of infection, the animals were sacrificed and immediately stored at $-70^{\circ} \mathrm{C}$. Later, the brain tissue $(0.2$ g/animal) was macerated and mixed with $0.8 \mathrm{~mL}$ of phosphate-buffered saline (PBS) containing $100 \mathrm{U} / \mathrm{mL}$ penicillin and $100 \mu \mathrm{g} / \mathrm{mL}$ streptomycin. The suspension was centrifuged at $10,000 \mathrm{~g}$ for $15 \mathrm{~min}$ at room temperature $\left(16^{\circ} \mathrm{C}\right)$. The viral load (VL) in different tissues of the adult mice from the different experimental groups was estimated by real time-polymerase chain reaction (RTPCR) when clinical symptoms became apparent.

Behavioural analysis - Burrowing - For 2 h per day (from 09:00 am-11:00 am) on two non-consecutive days the week before inoculation and two non-consecutive days between 2 d.p.i. and the day of sacrifice, each animal was placed in a plastic cage $(32 \mathrm{~cm} \times 39 \mathrm{~cm} \times 16.5$ $\mathrm{cm})$ containing a PVC tube $(20 \mathrm{~cm}$ long, $7.2 \mathrm{~cm}$ diameter) filled with $100 \mathrm{~g}$ of normal diet food pellets with the open end supported $3 \mathrm{~cm}$ above the floor. After the testing period, the remaining food in the cylinder was weighed and the mouse was returned to its collective cage. Burrowing is an ethological task highly sensitive to systemic inflammation (Cunningham et al. 2009).

Open field - The apparatus consisted of a grey wood box (chipboard coated) $(30 \mathrm{~cm} \times 30 \mathrm{~cm} \times 40 \mathrm{~cm})$ with the floor divided into $10-\mathrm{cm}$ squares. Once a week before inoculation and between d.p.i. 2 and the day of sacrifice, each animal was placed in the centre of the arena and
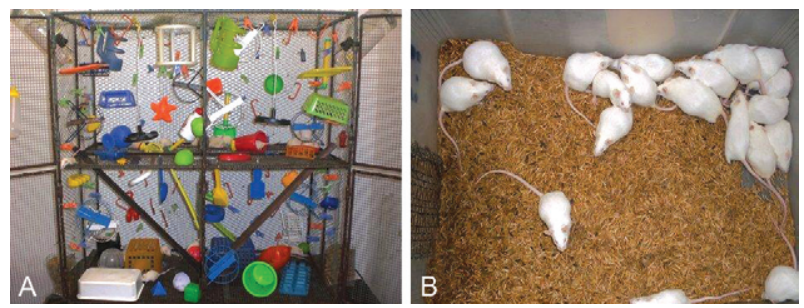

Fig. 2: environmental enrichment. Enriched environment (A) has been defined as social interactions with con-specifics and a stimulation of exploratory and motor behaviour with a variety of toys, ladders, tunnels, rope, bridges and running wheels for voluntary physical exercise changed periodically, as opposed to an impoverished environment (B) with reduced social interactions. kept in the apparatus for $5 \mathrm{~min}$, as previously described (Kinoshita et al. 2009). The open field test is a sensitive test for detecting sickness behaviour following a variety of viral infections, including dengue (de Miranda et al. 2012). A video camera connected to a computer was located $1 \mathrm{~m}$ above the open field and used to record each training session for later analysis with the AnyMaze software (Stöelting). The following parameters were analysed: distance travelled $(\mathrm{m})$, mean speed $(\mathrm{m} / \mathrm{s})$, crossed lines and immobility time (s). After each test, the open field was cleaned with $70 \%$ ethanol.

Online Supplementary data is provided in video format to illustrate some aspects of the methodology and the main effects of the environmental influences on AED in our murine model (videos 1, 2).

After the behavioural tests, all diseased animals that showed a reduction of more than $60 \%$ in burrowing activity for two consecutive measurements (4 sessions) clinical disease signs (see Results) or clinical symptoms were sacrificed with i.p. 1\% 2,2,2-tribromoethanol (0.01 $\mathrm{mL} / \mathrm{g}$ of body weight). Three animals from each group were processed for histopathology.

Histology and immunohistochemistry - Mice were transcardially perfused with heparinised saline followed by $4 \%$ paraformaldehyde in $0.1 \mathrm{M}$ phosphate buffer $(\mathrm{pH}$ 7.2-7.4). Livers and lungs, from five animals in each group were embedded in paraffin and sections $(3 \mu \mathrm{m}$ thick) were dewaxed in xylene, rehydrated with alcohols and stained with haematoxylin-eosin or immunolabelled to detect DENV3, CD-3, CD-15 and CD-20 antigens.

$T$ and $B$ lymphocytes - The specimens were fixed in $4 \%$ paraformaldehyde and embedded in paraffin. Serial $3-\mu \mathrm{m}$ cross-sections were made and the fragments were placed on glass slides previously treated with poly-Dlysine (Sigma Chemical Co, USA) and deparaffinised in xylene and descending ethanol series. Antigen retrieval was performed using pressure cooker heating (PAS$\mathrm{CAL}^{\circledR},{ }^{\circledR}$ DakoCytomation, USA) in citrate buffer $(10 \mathrm{mM}$, $\mathrm{pH}$ 6.0). After washing in PBS, the sections were immersed in $0.3 \%$ hydrogen peroxide for 5 min to block endogenous peroxidase activity and blocked with protein for $10 \mathrm{~min}$. The sections were then incubated in a dark wet chamber with primary monoclonal antibodies against CD3 (SP7 clone, dilution 1:400, DakoCytomation, USA) or CD20 (L26 clone, dilution 1:600, DakoCytomation, USA) for $30 \mathrm{~min}$ then a secondary antibody followed by a streptavidin-biotin-peroxidase complex, each for $20 \mathrm{~min}$ at room temperature (DakoCytomation, USA). The slides were visualised with diaminobenzidine and counterstained with Harry's haematoxylin.

Microglia immunolabelling - Free-floating vibratome (70 $\mu \mathrm{m}$ thick) brain sections were pre-treated with $0.2 \mathrm{M}$ boric acid ( $\mathrm{pH} \mathrm{9)}$ at $65-70^{\circ} \mathrm{C}$ for $60 \mathrm{~min}$ to improve antigen retrieval. The sections were incubated with a polyclonal antibody against ionised calcium binding adapter molecule $1(2 \mu \mathrm{g} / \mathrm{mL}$ in PBS $)$ to detect microglia and/or macrophages (anti-Iba1, \#019-19741; Wako Pure Chemical Industries Ltd, Osaka, Japan). Washed sections were then incubated overnight with a secondary antibody 
(goat anti-rabbit, 1:250 in PBS, Vector Laboratories). Endogenous peroxidases were inactivated by immersion in $3 \% \mathrm{H}_{2} \mathrm{O}_{2}$ in PBS. The PBS washed sections were transferred to a solution of avidin-biotin-peroxidase complex (VECTASTAIN ABC kit; Vector Laboratories) for $1 \mathrm{~h}$. The DAB/Nickel/Glucose Oxidase protocol was used to reveal immunolabelled antigenic sites (Shu et al. 1988). We confirmed the specificity of the immunohistochemical pattern by omitting the primary antibody (Saper \& Sawchenko 2003).

RNA extraction - Viral RNA was extracted from the supernatant of infected C6/36 cells using a QIAquick RNA extraction kit (Qiagen, Hilden, Germany) according to the manufacturer's instructions.

SYBR green quantitative RT-PCR (SYBR-qPCR) qRT-PCR was performed using a commercial kit (SuperScript III Platinum SYBR ${ }^{\circledR}$ Green One-step qRT-PCR, Invitrogen, Carlsbad, CA, USA) and the ABI Prism 7500 Real Time PCR System (Applied Biosystem, Carlsbad, CA, USA). The reaction were performed in a final volume of $25 \mu \mathrm{L}$ containing $5 \mu \mathrm{L}$ of viral RNA (1-2 ng/ $\mu \mathrm{L}), 0.5 \mu \mathrm{L}$ of SuperScript III RT Platinum Taq Mix, $0.2 \mu \mathrm{M}$ of each DENV primer (dos Santos et al. 2008), $12.5 \mu \mathrm{L}$ of $2 \times$ SYBR Green fluorescent dye and $1 \mu \mathrm{L}$ of ROX dye. The amplification was performed as follows: $50^{\circ} \mathrm{C}$ for $20 \mathrm{~min}, 95^{\circ} \mathrm{C}$ for $5 \mathrm{~min}, 45$ cycles of $95^{\circ} \mathrm{C}$ for $15 \mathrm{~s}, 55^{\circ} \mathrm{C}$ for $40 \mathrm{~s}$ and $72^{\circ} \mathrm{C}$ for $30 \mathrm{~s}$. The melting curve was calculated during the incubation period from $60-90^{\circ} \mathrm{C}$ with a capture speed of $0.2^{\circ} \mathrm{C} / \mathrm{s}$. Each sample was analysed in duplicate wells. The SYBR-qRT-PCR results were expressed as genome copies/mL based on the standard curve constructed from the amplification of RNA extracted from $\mathrm{C} 6 / 36$ cells infected with the DENV-3 strain BH 692808 (stock in concentration: 3.1 $\times 10^{6}$ genome copies $/ \mathrm{mL}$ ) and diluted from $10^{-1}$ to $10^{-6}$. Estimations of the VL (genome copies/mL) in the C636 cell culture supernatants corresponding to the ROND 2929 and ROND 3115 human cases were $1.30 \times 10^{3}-1.33$ $\times 10^{3}$ and $7.77 \times 10^{3}-7.82 \times 10^{3}$, respectively.

Standard curve - External standard curves were generated from serial dilutions of RNA derived from aliquots with known viral titres covering a range from $1 \times 10^{-1}-1 \times 10^{-8}$. A standard curve with eight points was amplified in duplicate along with non-template controls to determine the threshold value. Cycle threshold values from each RNA sample were compared with external standard curves to determine the corresponding virus loads in each tissue.

\section{RESULTS}

Clinical signs and survival - Burrowing and open field tests (movie S3) were performed in control animals until significant changes in both tests became apparent at 56 d.p.i. (Fig. 3A-D). After serial DENV3 single-serotype inoculations, these changes were detected at eight

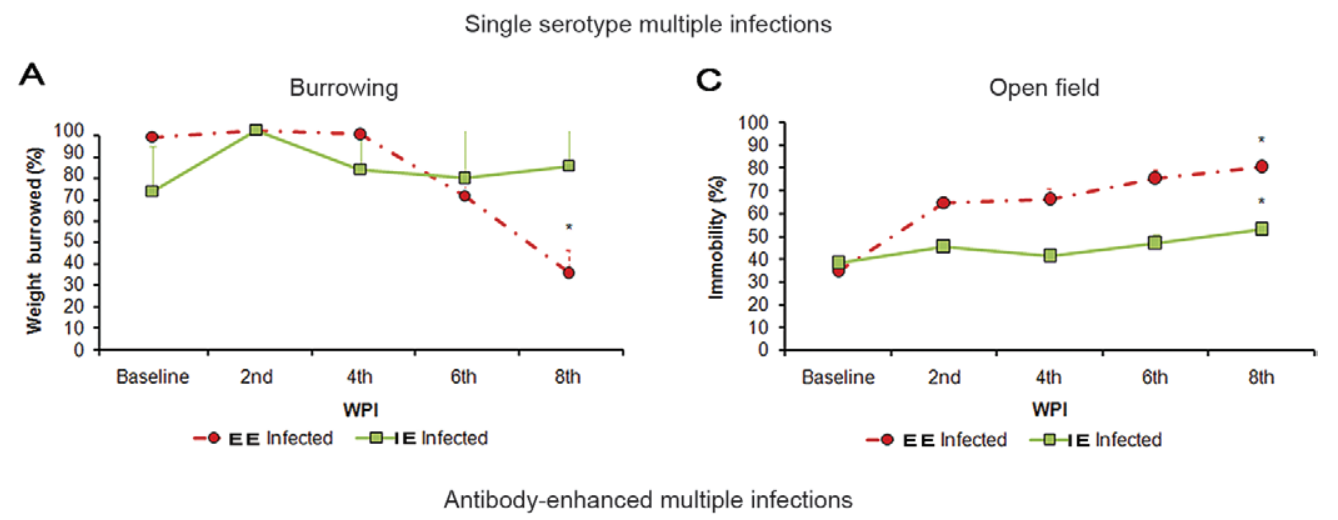

B
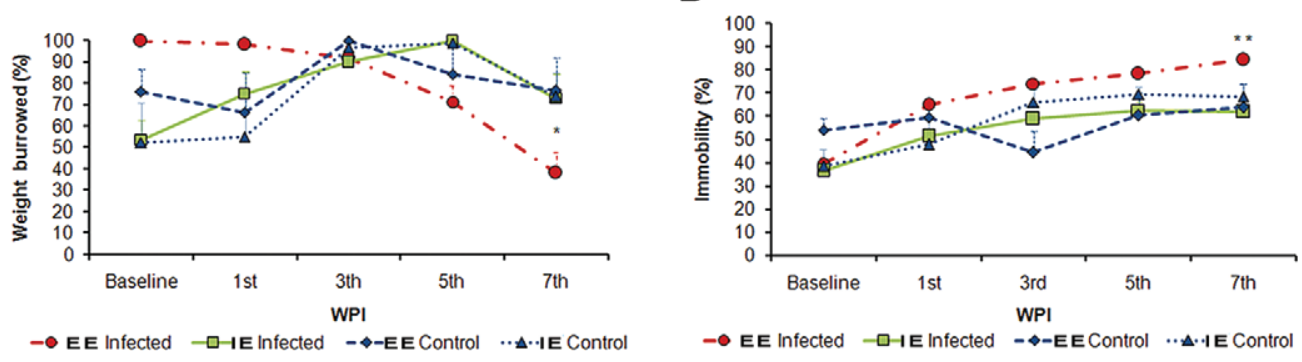

Fig. 3: sickness behaviour. Graphic representation of the behavioural changes with respective error bars in the albino Swiss mouse model of multiple single serotype multiple infections [A, C: single serotype (SS) group; B, D: antibody-enhanced dengue disease group (AED)]. As compared to baseline measurements, dengue virus (DENV)3 SS multiple infections induced significant decrease in borrowed food only in enriched environment (EE) subjects (A). On average, the subjects from EE $(n=15)$ submitted to AED showed, as compared with base line, significant less burrowed food at seven weeks post-inoculation (wpi) whereas the subjects with impoverished environmental (IE) ( $\mathrm{n}=13)$ did not change significantly (B). Open-field tests from all subjects submitted to serial SS infections (C) or to an AED (D) appeared significantly altered at 8 wpy. Control animals did not show any significant changes. Asterisks mean $\mathrm{p}<0.05$. 
weeks post-inoculation (wpi) with a significant decrease in burrowed food for the EE animals (EE baseline = $96.82 \pm 8.21 \%$ vs. $\mathrm{EE} 8 \mathrm{wpi}=35.04 \pm 9.31 \%$; one-way ANOVA, Bonferroni a priori test, $\mathrm{p}<0.05$ ), but not for the IE animals (IE baseline $=72.31 \pm 6.94 \%$ vs. $83.75 \pm$ $9.9 \% ; p>0.05$ ) (Fig. 3A). In the antibody-enhanced dengue disease group at $7 \mathrm{wpi}$, the EE mice showed a significant decrease in burrowed food (EE baseline $=100 \%$ $\pm 2.74 \%$ vs. EE $8 \mathrm{wpi}=34.23 \pm 16.95)$, with a reduction of $65.77 \%$ (one-way ANOVA, Bonferroni a priori test, $\mathrm{p}<0.05)$ whereas the IE mice did not change burrowing activity (Fig. 3B). In the open field tests at the same time points, all multiple single-serotype infected (Fig. 3C) and multiply infected, antibody-enhanced (Fig. 3D) groups showed a significant increase in immobility time. The multiple single-serotype infected groups housed an EE (57\%) and IE (28\%) as well as multiple infected AED housed in EE (45\%) and IE (25.35\%) showed increases in immobility time compared with base line (one-way ANOVA, Bonferroni a priori test, $\mathrm{p}<0.05$ ). None of the control groups showed any significant changes. Although these clinical signs could be associated with central nervous system (CNS) changes, we did not observe any microglial morphological changes that could be interpreted as CNS inflammation (Supplementary data).

Fig. 4A illustrates the survival curves after multiple infections with a SS of DENV3. Although the EE mice presented higher rates of mortality and disease symptoms $(40 \%)$ compared with the IE $(23.1 \%)$ after multiple single-serotype infections, the Kaplan-Meyer survival plot did not show any significant differences between the survival curves in this experiment (Kaplan-Meyer log rank test $p=0.089$ ). Compared with the mice subjected to the AED protocol, the mice that received multiple infections with a SS not only survived for longer periods post-challenge, but exhibited fewer clinical signs. Fol- lowing the AED protocol (Fig. 4B), the EE mice showed earlier and more intense clinical signs, including dyspnoea, tremor, hunched posture, ruffled fur, immobility, pre-terminal paralysis, shock and deaths compared with the mice in the IE (Supplementary data, video 2). Kaplan-Meyer analysis revealed significant differences in the survival probability curves of the AED experimental groups (uninfected, EE and IE; log-rank test, $\mathrm{p}=$ 0.0025) (Fig. 4B).

To prevent death and reduce clinical symptoms in the AED subjects, we injected the mice in this group with glucocorticoids at 38 d.p.i. After a single dose of glucocorticoids (arrow in Fig. 4C), clinical signs and deaths were reduced and the survival probability curve stabilized four-six weeks in the IE and EE experimental groups despite continued efforts to induce AED during this period by maintaining the regime of multiple inoculations. Approximately 50 days after the glucocorticoids injection, however, a progressive decline in the survival probability was observed. In the EE and IE groups, the AED animals injected with corticoids showed increased survival probabilities (log-rank test, $\mathrm{p}=0.016$ ).

There were no significant differences in the survival probability curves between the control and infected subjects treated with the SS protocol $(p=0.089)$, but the AED protocol did produce significant differences $(p=$ 0.0025 ). In addition, a significant difference was observed between the AED regimen involving infection with multiple serotypes and the animals that were infected with multiple doses of a SS ( $\mathrm{SS}=68.13 \pm 2.93$ vs. $\mathrm{AED}=54.37 \pm 5.96$ d.p.i.; two-tail T-test $\mathrm{p}=0.029$ ).

None of the control animals injected with uninfected brain homogenate showed any significant changes in survival probability.

Pathological changes after AED infection - The histological analysis of livers and lungs used a semiquanti-
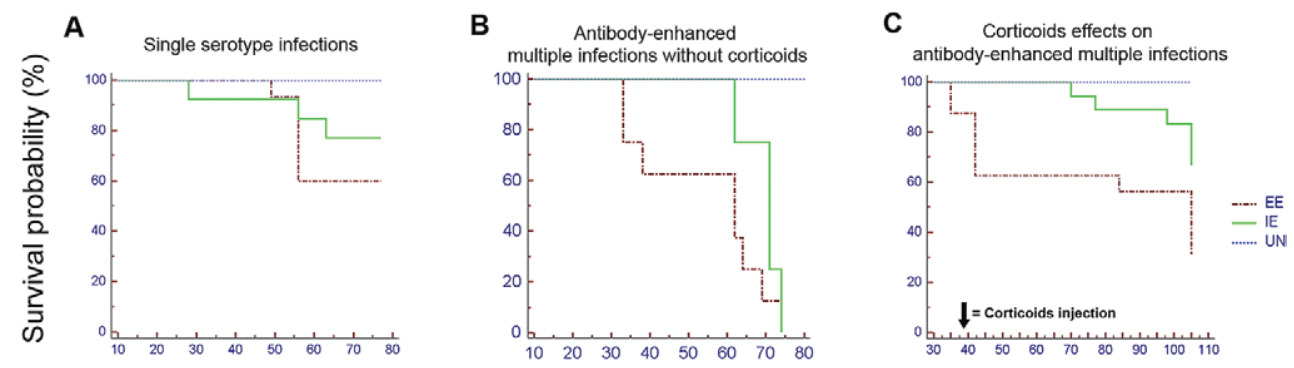

\section{Days after first infection}

Fig. 4A: survival probability after serial single serotype (SS) dengue virus (DENV)3 multiple infections. Kaplan-Meier survivals plot after SS DENV multiple infections. Note that as compared to the serial antibody-enhanced dengue disease (AED) (B), animals infected with a SS [DENV3 (genotype III)] survived for longer periods post-challenge without disease signs. Kaplan-Meyer analysis of the survival probabilities did not reveal significant results (log rank test $\mathrm{p}=0.27$ ). Control animals did not show any change in the survival plot; B: survival probability after AED with no corticoids injection. Kaplan-Meier survival plot after AED infection ( $\log$ rank test $p=0.0025)$. Note faster decrease of survival probability in the subjects from enriched environment as compared with subjects from impoverished environment (IE). To stop deaths and reduce the intensity of clinical symptoms we started glucocorticoid treatment (C). A plateau in the survival probability of experimental groups following glucocorticoid injection (arrow) suggests that the reduction of clinical symptoms and deaths during the plateau may be associated with an anti-inflammatory effect. Kaplan-Meier survival plot after AED infection ( $\log$ rank test $p=0.016$ ). Note faster decrease of survival probability in the subjects from enriched environment (EE) as compared with subjects from IE. Control animals did not show any significant differences. UN: uninfected group. 
tative protocol to assess lesion severity. After treatment with the antibody-enhanced regimen involving multiple infections, the tissue samples showed frequent inflammatory infiltrates, dominated by T-lymphocytes $(++++)$ and rare $(+)$ B-lymphocytes $\left(\mathrm{CD} 20^{+}\right)$, macrophages $\left(\mathrm{CD} 68^{+}\right)$and neutrophils $\left(\mathrm{CD} 15^{+}\right)$. The subjects housed in the enriched environments showed intense $(++++)$

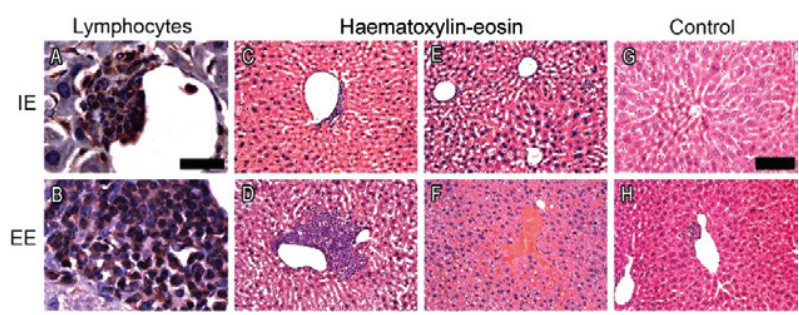

Fig. 5: liver pathology after antibody-enhanced dengue disease. Photomicrographics from immunolabelled (A-B) or haematoxylin-eosin $(\mathrm{C}-\mathrm{H})$ stained sections to illustrate pathological changes in the liver of impoverished environment (IE) $(n=4)$, enriched environment (EE) ( $n$ $=4)$ and control uninfected $(n=4)$ subjects. A, B: immunohistochemistry for $\mathrm{T}\left(\mathrm{CD}^{+}\right)$lymphocytes counterstained by Harry's haematoxylin. Note that the inflammatory mononuclear infiltration in the subendothelial space of peri-efferent veins was less intense (++) in IE (A, C) as compared with $\mathrm{EE}(++++)(\mathrm{B}, \mathrm{D})$. Intense vascular congestion was found in $\mathrm{EE}(\mathrm{F})$. Steatosis, vascular congestion and mononuclear infiltration was rare and less intense $(+)$ in the uninfected control subjects $(\mathrm{G}, \mathrm{H})$. [Bars $=$ high power $(25 \mu \mathrm{m})$; low power $(125 \mu \mathrm{m})]$.

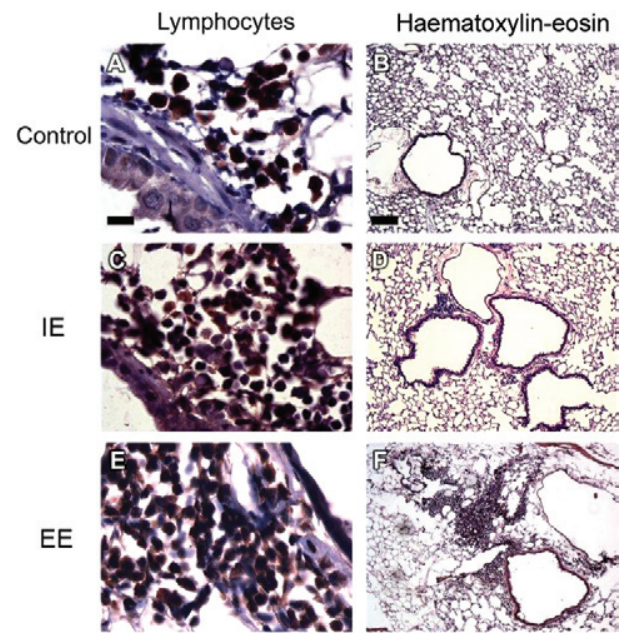

Fig. 6: lung pathology after antibody-enhanced dengue disease (AED). Photomicrographics from immunolabelled (A, C, E) and haematoxylin-eosin (H\&E) (B, D, F) stained sections to illustrate pathological changes in the lungs of control uninfected $(n=4)$, impoverished environment (IE) $(n=4)$ and enriched environment $(\mathrm{EE})$ $(\mathrm{n}=4)$ subjects, after AED infection. A, C, E: immunohistochemistry for T $\left(\mathrm{CD}^{+}\right)$lymphocytes counterstained by Harry's haematoxylin. Note that the inflammatory T (CD3) lymphocytic hyperplasia in the peribronchical space was less intense in IE (C) than in EE (E). Consistent with this, mononuclear infiltration in the peribronchical space, as revealed by H\&E staining, was less intense in IE (D) as compared to $\mathrm{EE}(\mathrm{F})$. Mononuclear infiltration was not significant in the lungs of uninfected control subjects (A, B) hyperplasia of $\mathrm{T}$ lymphocytes in the liver (Fig. 5B, D), whereas this was moderate $(++)$ in the IE mice (Figs $4 \mathrm{C}$, $5 \mathrm{~A})$ and rare $(+)$ in the uninfected subjects (Fig. $5 \mathrm{H})$. In addition, discrete tumefaction, microvesicular steatosis and Kupffer cell hypertrophy were detected in various liver lobules with the previously mentioned $\mathrm{T}$ lymphocytic hyperplasia around the efferent veins. Liver vascular congestion was mainly found in EE mice (Fig. 5F). These pathological features were rare and less intense in the uninfected subjects (Fig. 5G, H).

Similar inflammatory infiltrates with dominant Tlymphocytic hyperplasia were also presented in the peribronchial space (Fig. 6). Animals housed in the IE (Fig. 6C, D) showed a lesser degree of T-lymphocytic hyperplasia compared with those housed in the EE (Fig. 6E, F). These changes were less intense and rarely detected in the lungs of the uninfected control subjects (Fig. 6A, B).

To illustrate the presence of viral infection in the parenchyma we selected photomicrographs of sections from lungs (Fig. 7) and livers (Fig. 8) of infected animals under the AED multiple infections regime immunolabelled for viral antigens.

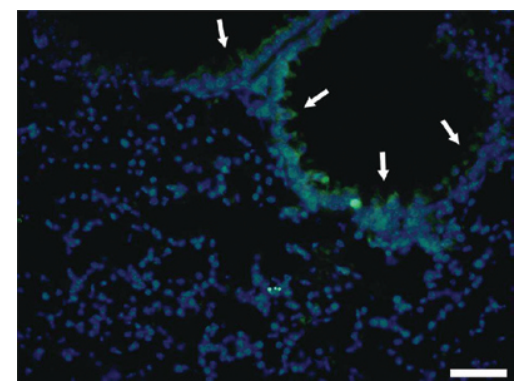

Fig. 7: photomicrography of lung immunolabelled section from antibody-enhanced dengue disease individual obtained by indirect immunofluorescence to illustrate the presence of dengue virus (DENV)3 fluorescein labelled viral antigens (green), counterstained by 4'-6-diamidino-2-phenylindole fluorescence for DNA (blue) in the peribronchical space. Arrows indicate immunopositive cells for DENV3 antigens.

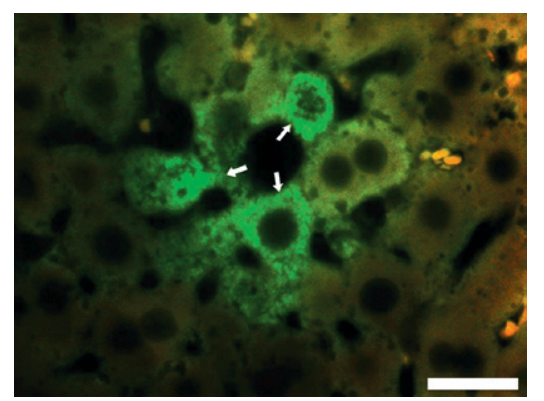

Fig. 8: photomicrography of liver immunolabelled section from antibody-enhanced dengue disease individual obtained by indirect immunofluorescence to illustrate the presence of dengue virus (DENV)3 fluorescein labelled viral antigens (green) in the parenchyma near the peri-efferent vein. Arrows indicate immunopositive cells for DENV3 antigens. 
qRT-PCR to detect DENV3 - Low viral titres were detected $24 \mathrm{~h}$ after the last DENV3 inoculation, at which time clinical signs became apparent. The highest concentrations of viral DNA were found in the livers of subjects housed in the EE (3.03 copies $/ \mathrm{mL}$ ). This was significantly different from the concentrations observed in the spleen $(0.26$ copies $/ \mathrm{mL})$ and lungs $(0.003$ copies/ $\mathrm{mL}$ ) of the same animals, but no significant differences were observed between the number of viral genome copies $/ \mathrm{mL}$ in the EE and IE subjects.

\section{DISCUSSION}

In this study we tested the effects of environmental enrichment on dengue disease progression in a model of AED in adult female mice, in which serial inoculations of anti-DENV2 antibodies were followed $24 \mathrm{~h}$ later by inoculation with DENV3 (genotype III) infected brain homogenate. We found that subjects housed in EE with AED presented more intense clinical symptoms and higher mortality than subjects housed in impoverished environment and clinical signs were associated with $\mathrm{T}$ lymphocytic hyperplasia in the liver and lungs where we found cells expressing DENV antigens.

Under the of antibody-enhanced response regime, multiple inoculations with anti-DENV2 antibodies were followed $24 \mathrm{~h}$ later by inoculation with DENV3 genotype III. This regimen was associated with a higher number of deaths in the EE group than in the IE group. One hour after virus infection under this regime a number of the AED animals developed intense clinical signs with exuberant dyspnoea followed by death. TNF derived from DENV infected monocytes and activated Tcells has been proposed as a major mediator responsible for the deregulation of endothelial cells, which lead to plasma leakage (Halstead 2007). In addition, DENV infection causes mast-cell to trigger endothelial cell activation (Brown et al. 2011) and the release of vascular endothelial growth factor and proteases during dengue shock syndrome (Furuta et al. 2012); mast-cell numbers are also increased in peribronchiolar spaces and areas adjacent to the inter-alveolar septa (Barreto et al. 2007).

Taken together these data suggest that, during serial AED, environmental influences on disease progression might contribute to the disease severity by inducing an exacerbated inflammatory response. Indeed an EE has been shown to enhances T-cell activity during viral infections (de Sousa et al. 2011) and DENV is associated with increasing frequencies of interferon (IFN)- $\gamma$ and TNF- $\alpha$ producing T-cells after primary infection with all DENV serotypes; secondary infection enhances these responses (Beaumier et al. 2010). In a previous report, T-cell responses to sequential infections were measured after mice were immunized with different DENV serotypes and the frequency of peptide-specific T-cells after infection was determined (Beaumier et al. 2008). After heterologous secondary infection in BALB/c mice the acute response was enhanced compared with the acute response after primary infection (Beaumier et al. 2008). However, the passive administration of anti-DENV antibodies against one DENV serotype followed $24 \mathrm{~h}$ later by inoculation of another serotype of DENV was sufficient to enhance DENV infection and disease in AG129 mice. This was the first model of AED lethal in vivo (Balsitis et al. 2010).

Because we did not assess any inflammatory mediators, it remains to be investigated whether increased cytokine production in subjects housed in EE may contributes to the differences in disease severity and mortality rates from subjects housed in impoverished environments. In line with this hypothesis, the anti-inflammatory effects glucocorticoids injection stabilized the survival curves of both experimental groups for 50 days (see plateau following corticoid injection in Fig. 4C) which not occur in the individuals that did not received corticosteroids (Fig. 4B). Because corticosteroids reduce T-lymphocyte proliferation (Lu et al. 2010), we suggest that a relative decrease in the number of T-lymphocytes following glucocorticoid injection may explain the reduction in mortality and disease symptoms. A previous report demonstrated that dexamethasone completely inhibits cytokine production after a peripheral challenge with lipopolysaccharide (Teeling et al. 2010). Delayed but not early glucocorticoid treatment has also been shown to protects the host, increase survival and decrease cerebral damage during experimental herpes simplex virus encephalitis in mice (Sergerie et al. 2007). Because delayed administration of glucocorticoids reduced death and disease severity after serial AED it is reasonable to suggest that the cytokine storm previously observed in secondary DENV infection (Rothman 2009, Guabiraba et al. 2010, Tan et al. 2010) and AED (Balsitis et al. 2010) may be inhibited by corticoids (Sergerie et al. 2007).

A previous report showed a single intracerebral inoculation with DENV-3 (genotype I) induced neurological disease and death in mice, whereas DENV-3 (genotype III) did not (Ferreira et al. 2010). Consistent with this result, we showed that neither neurological clinical signs such as preterminal paralysis nor behavioural changes, such as a $60 \%$ reduction in burrowing activity were accompanied by evident pathology in the CNS (Supplementary data).

However, the results obtained with the singly-serotype regimen suggest that the adaptive immune response may have induced efficient protection against primary DENV infection. Indeed no significant differences were found between the experimental groups under the SS multiple infections protocol. The resistance to dengue infection after primary infection may be consistent with previous results showing that the resistance was not due to a defect in the recruitment of effectors lymphocytes, but rather to the antiviral activity of those cells, which promoted viral clearance (Ip \& Liao 2010). Consistent with this hypothesis, antiviral activity that promotes viral clearance in a manner that depends on IFN- $\gamma$ and TNF- $\alpha$-producing T-cells directed at $\mathrm{H}-2 \mathrm{Db}$-restricted epitopes (Friberg et al. 2011) may be responsible for the resistance of mice to primary infection by dengue virus. We suggested that a serial SS infection may mimic a severe primary dengue infection in which others have described a cytokine storm associated with a T-lymphocyte response, that is mostly responsible for the development of disease rather than protection against severe infection (Rothman 2009, Guabiraba et al. 2010). 
We report for the first time that after a regimen of multiple infections associated with and AED model, animals maintained in an EE showed more intense clinical symptoms and behavioural changes with lower disease resolution compared with animals maintained in impoverished housing.

\section{REFERENCES}

Balsitis SJ, Williams KL, Lachica R, Flores D, Kyle JL, Mehlhop E, Johnson S, Diamond MS, Beatty PR, Harris E 2010. Lethal antibody enhancement of dengue disease in mice is prevented by Fc modification. PLoS Pathog 6: e1000790.

Barreto DF, Takiya CM, Schatzmayr HG, Nogueira RMR, Farias-Filho J da C, Barth OM 2007. Histopathological and ultrastructural aspects of mice lungs experimentally infected with dengue virus serotype 2. Mem Inst Oswaldo Cruz 102: 175-182.

Beaumier CM, Mathew A, Bashyam HS, Rothman AL 2008. Crossreactive memory $\mathrm{CD} 8(+) \mathrm{T}$ cells alter the immune response to heterologous secondary dengue virus infections in mice in a sequence-specific manner. J Infect Dis 197: 608-617.

Beaumier CM, Jaiswal S, West KY, Friberg H, Mathew A, Rothman AL 2010. Differential in vivo clearance and response to secondary heterologous infections by $\mathrm{H} 2$ (b)-restricted dengue virusspecific CD8 ${ }^{+} \mathrm{T}$ cells. Viral Immunol 23: 477-485.

Boonnak K, Dambach KM, Donofrio GC, Tassaneetrithep B, Marovich MA 2011. Cell type specificity and host genetic polymorphisms influence antibody-dependent enhancement of dengue virus infection. $J$ Virol 85: 1671-1683.

Brown MG, Hermann LL, Issekutz AC, Marshall JS, Rowter D, AlAfif A, Anderson R 2011. dengue virus infection of mast cells triggers endothelial cell activation. J Virol 85: 1145-1150.

Cunningham C, Campion S, Lunnon K, Murray CL, Woods JFC, Deacon RMJ, Rawlins JNP, Perry VH 2009. Systemic inflammation induces acute behavioral and cognitive changes and accelerates neurodegenerative disease. Biol Psychiatry 65: 304-312.

Daughaday CC, Brandt WE, McCown JM, Russell PK 1981. Evidence for two mechanisms of dengue virus infection of adherent human monocytes: trypsin-sensitive virus receptors and trypsin-resistant immune complex receptors. Infect Immun 32: 469-473.

de Miranda AS, Rodrigues DH, Amaral DC, de Lima Campos RD, Cisalpino D, Vilela MC, Lacerda-Queiroz N, de Souza KP, Vago JP, Campos MA, Kroon EG, da Gloria de Souza D, Teixeira MM, Teixeira AL, Rachid MA 2012. Dengue-3 encephalitis promotes anxiety-like behavior in mice. Behav Brain Res 230: 237-242.

de-Oliveira-Pinto LM, Gandini M, Freitas LP, Siqueira MM, Marinho CF, Setúbal S, Kubelka CF, Cruz OG, de Oliveira SA 2012. Profile of circulating levels of IL-1Ra, CXCL10/IP-10, CCL4/MIP$1 \beta$ and CCL2/MCP-1 in dengue fever and parvovirosis. Mem Inst Oswaldo Cruz 107: 48-56.

de Sousa AA, Reis R, Bento-Torres J, Trevia N, Lins NA, Passos A, Santos Z, Diniz JA, Vasconcelos PF, Cunningham C, Perry VH, Diniz CW 2011. Influence of enriched environment on viral encephalitis outcomes: behavioral and neuropathological changes in albino Swiss mice. PLOS ONE 6: e15597.

dos Santos HW, Poloni TR, Souza KP, Muller VD, Tremeschin F, Nali LC, Fantinatti LR, Amarilla AA, Castro HL, Nunes MR, Casseb SM, Vasconcelos PF, Badra SJ, Figueiredo LT, Aquino VH 2008. A simple one-step real-time RT-PCR for diagnosis of dengue virus infection. J Med Virol 80: 1426-1433.

Ferreira GP, Figueiredo LB, Coelho LF, PA Jr S, Cecilio AB, Ferreira PC, Bonjardim CA, Arantes RM, Campos MA, Kroon EG 2010. Dengue virus 3 clinical isolates show different patterns of virulence in experimental mice infection. Microbes Infect 12: 546-554.
Friberg H, Burns L, Woda M, Kalayanarooj S, Endy TP, Stephens HA, Green S, Rothman AL, Mathew A 2011. Memory CD8 ${ }^{+} \mathrm{T}$ cells from naturally acquired primary dengue virus infection are highly cross-reactive. Immunol Cell Biol 89: 122-129.

Furuta T, Murao LA, Lan NT, Huy NT, Huong VT, Thuy TT, Tham VD, Nga CT, Ha TT, Ohmoto Y, Kikuchi M, Morita K, Yasunami M, Hirayama K, Watanabe N 2012. Association of mast cell-derived VEGF and proteases in dengue shock syndrome. PLoS Negl Trop Dis 6: e1505.

Gibbons RV, Kalanarooj S, Jarman RG, Nisalak A, Vaughn DW, Endy TP, Mammen Jr MP, Srikiatkhachorn A 2007. Analysis of repeat hospital admissions for dengue to estimate the frequency of third or fourth dengue infections resulting in admissions and dengue hemorrhagic fever and serotype sequences. Am J Trop Med Hyg 77: 910-913.

Guabiraba R, Marques RE, Besnard AG, Fagundes CT, Souza DG, Ryffel B, Teixeira MM 2010. Role of the chemokine receptors CCR1, CCR2 and CCR4 in the pathogenesis of experimental dengue infection in mice. PLOS ONE 5: e15680.

Gubler DJ, Meltzer M 1999. Impact of dengue/dengue hemorrhagic fever on the developing world. Adv Virus Res 53: 35-70.

Halstead SB 2007. Dengue. Lancet 370: 1644-1652.

Hober D, Poli L, Roblin B, Gestas P, Chungue E, Granic G, Imbert P, Pecarere JL, Vergez-Pascal R, Wattre P, et al. 1993. Serum levels of tumor necrosis factor-alpha (TNF-alpha), interleukin-6 (IL-6), and interleukin-1 beta (IL-1 beta) in dengue-infected patients. Am J Trop Med Hyg 48: 324-331.

Ip PP, Liao F 2010. Resistance to dengue virus infection in mice is potentiated by CXCL10 and is independent of CXCL10-mediated leukocyte recruitment. J Immunol 184: 5705-5714.

Jessie K, Fong MY, Devi S, Lam SK, Wong KT 2004. Localization of dengue virus in naturally infected human tissues by immunohistochemistry and in situ hybridization. J Infect Dis 189: 1411-1418.

Kangwanpong D, Bhamarapravati N, Lucia HL 1995. Diagnosing dengue virus infection in archived autopsy tissues by means of the in situ PCR method: a case report. Clin Diagn Virol 3: 165-172.

Kinoshita D, Cohn DW, Costa-Pinto FA, de Sa-Rocha LC 2009. Behavioral effects of LPS in adult, middle-aged and aged mice. Physiol Behav 96: 328-332.

Kurane I, Ennis FE 1992. Immunity and immunopathology in dengue virus infections. Semin Immunol 4: 121-127.

Lu YS, Pu LY, Li XC, Wang XH 2010. Methylprednisolone inhibits activated $\mathrm{CD}^{+} \mathrm{T}$ cell survival promoted by toll-like receptor ligands. Hepatobiliary Pancreat Dis Int 9: 376-383.

Mathew A, Rothman AL 2008. Understanding the contribution of cellular immunity to dengue disease pathogenesis. Immunol Rev 225: $300-313$

Nguyen TH, Lei HY, Nguyen TL, Lin YS, Huang KJ, Le BL, Lin CF, Yeh TM, Do QH, Vu TQ, Chen LC, Huang JH, Lam TM, Liu CC, Halstead SB 2004. Dengue hemorrhagic fever in infants: a study of clinical and cytokine profiles. J Infect Dis 189: 221-232.

Rothman AL 2009. T lymphocyte responses to heterologous secondary dengue virus infections. Ann NY Acad Sci 1171: e36-41.

Rothman AL 2010. Cellular immunology of sequential dengue virus infection and its role in disease pathogenesis. Curr Top Microbiol Immunol 338: 83-98.

Ruangjirachuporn W, Boonpucknavig S, Nimmanitya S 1979. Circulating immune complexes in serum from patients with dengue haemorrhagic fever. Clin Exp Immunol 36: 46-53.

Saper CB, Sawchenko PE 2003. Magic peptides, magic antibodies: guidelines for appropriate controls for immunohistochemistry. $J$ Comp Neurol 465: 161-163. 
Sergerie Y, Boivin G, Gosselin D, Rivest S 2007. Delayed but not early glucocorticoid treatment protects the host during experimental herpes simplex virus encephalitis in mice. $J$ Infect Dis 195: 817-825.

Shu SY, Ju G, Fan LZ 1988. The glucose oxidase-DAB-nickel method in peroxidase histochemistry of the nervous system. Neurosci Lett 85: 169-171.

Suaya JA, Shepard DS, Siqueira JB, Martelli CT, Lum LC, Tan LH, Kongsin S, Jiamton S, Garrido F, Montoya R, Armien B, Huy R, Castillo L, Caram M, Sah BK, Sughayyar R, Tyo KR, Halstead SB 2009. Cost of dengue cases in eight countries in the Americas and Asia: a prospective study. Am J Trop Med Hyg 80: 846-855.

Tan GK, Ng JK, Trasti SL, Schul W, Yip G, Alonso S 2010. A non mouse-adapted dengue virus strain as a new model of severe dengue infection in AG129 mice. PLoS Negl Trop Dis 4: e672.

Teeling JL, Cunningham C, Newman TA, Perry VH 2010. The effect of non-steroidal anti-inflammatory agents on behavioural changes and cytokine production following systemic inflammation: implications for a role of COX-1. Brain Behav Immun 24: 409-419.

Thomas SJ, Strickman D, Vaughn DW 2003. Dengue epidemiology: virus epidemiology, ecology and emergence. Adv Virus Res 61: 235-289.

van Praag, Kempermann G, Gage FH 2000. Neural consequences of enviromental enrichement. Nat Rev Neurosci 1: 191-198.

Vitarana T, de Silva H, Withana N, Gunasekera C 1991. Elevated tumour necrosis factor in dengue fever and dengue haemorrhagic fever. Ceylon Med J 36: 63-65.

Wang WK, Chao DY, Kao CL, Wu HC, Liu YC, Li CM, Lin SC, Ho ST, Huang JH, King CC 2003. High levels of plasma dengue viral load during defervescence in patients with dengue hemorrhagic fever: implications for pathogenesis. Virology 305: 330-338.

Wang WK, Chen HL, Yang CF, Hsieh SC, Juan CC, Chang SM, Yu CC, Lin LH, Huang JH, King CC 2006. Slower rates of clearance of viral load and virus-containing immune complexes in patients with dengue hemorrhagic fever. Clin Infect Dis 43: 1023-1030. 


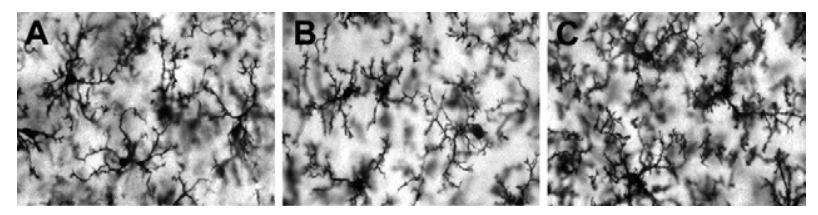

Microglial morphology of mice septal region after antibody-enhanced dengue disease infection and uninfected groups. A: control young uninfected subject; B: impoverished environment infected young subject: C: enriched environment (EE) infected young subject. No remarkable neuropathological changes were detected in the infected groups as compared with control subject, except by a subtle change in the apparent number of spiny-like processes in EE microglial cells.

\section{VIDEO 1 : a time-lapse movie of enriched and impoverished environments.}

VIDEO 2 : a time-lapse movie of clinical symptoms of individuals that were maintained in enriched and impoverished environments.

VIDEO 3 : a time-lapse movie of burrowing and open field activities. 